\title{
Deep Sequencing Analysis of the Eha-Regulated Transcriptome of Edwardsiella tarda Following Acidification
}

\author{
Gao $D^{1 *}$, Liu N1', Li Y1, Zhang $\mathbf{Y}^{1}$, Liu G², Xiao G² and Lu C ${ }^{2}$
}

${ }^{1}$ Department of Pathogenic Microbiology and Immunology, Southeast University School of Medicine, Nanjing, China

${ }^{2}$ Nanjing Agricultural University, College of Veterinary Medicine, Nanjing, China

\begin{abstract}
Eha is a virulence regulator associated with the replication of Edwardsiella tarda within RAW264.7 macrophages. Eha is required for the bacteria to resist the acid and oxidative stress in macrophages. We herein demonstrate that Eha regulates the resistance of this bacterium against acidification in macrophages and explain the underlying molecular mechanism. Firstly, to find an acid or oxidative condition to induce the strongest Eha activities, we constructed pMP220 Pehalac $Z$ plasmid and inspected the lac $Z$ expression regulated by Eha by using a $\beta$-galactosidase assay. At exposure of pH6.3 medium $2 \mathrm{~h}$, whole transcriptomic profiling of the wild type and mutant were performed by RNA-sequencing. We identified 147 differentially -expressed genes (DEGs) ( $\mid \log 2$ ratio| $\geq 1$ ), 113 and 34 of which were significantly up- and down-regulated, respectively, in the mutant compared with the wild type. These findings were validated by qRT-PCR. A CO functional analysis revealed that these genes were divided into 25 categories, including the bacterial processing, localization, metabolism, combination, catalysis, transportation and cellular composition. Based on the KEGG database, these genes were distributed in 55 pathways, such as the two-component system, ABC transporters, and microbial metabolism. At last, the intracellular survival rates and intraphagosomal $\mathrm{pH}$ of wild type ET 13 and its eha mutant in bafilomycin-treated and untreated macrophages were measured. The experiment showed that Eha was involved in protecting the bacteria from the effects of acidification within macrophages. The survival rate of the wild was also higher than that of the mutant under acid stress both in vivo and in vitro $(\mathrm{P}<0.05)$. Overall, Eha was found to regulate 147 genes that affect bacterial metabolism and virulence, allowing the bacteria to adapt to an acidic environment. These results could be helpful for further investigations of the mechanisms by which Edwardsiella tarda survives in macrophages.
\end{abstract}

Key words: Eha gene; E. tarda; RNA-seq; Macrophage; Acidification

\section{Introduction}

Edwardsiella tarda (E. tarda) is a facultative intracellular pathogen that causes Edwardsiellosis in freshwater and marine fish worldwide and a Salmonella-like gastroenteritis in humans [1,2]. Macrophages play critical roles in the defense against invading bacteria. Zhang et al. showed that $E$. tarda can utilize macrophages as a niche to initiate its virulence and spread systemic infections [3]. However, there are various stressful conditions such as nutrition deprivation, low $\mathrm{pH}$ and high reactive oxygen species (ROS) present in the intracellular niche of the phagocytes [4]. There are the strategies that virulent bacterial strains use to evade phagosomes and escape into the cytosol to enable their survival in the cells [5]. E. tarda could live and multiply in macrophages, and escape from the cells. It is important for the bacterium to lead to extra intestinal diseases and systemic infections [6]. E. tarda is capable to detoxify ROS by generating catalase (Kat) and superoxide dismutase (Sod) to survive within macrophages $[7,8]$. Okuda et al. suggested that the bacterial type III secretion system is able to interfere with the formation of acid stress in phagosomes to facilitate its replication in macrophages [9]. However, little other information is available about how $E$. tarda is affected by an acidic environment.

Some findings have been reported about the changes that occur in other intracellular pathogens in response to acid stress in macrophages. For example, Rathman et al. suggested that an acidic environment in Salmonella-containing phagosomes is necessary for the bacterial survival and replication within the macrophage [10]. Supporting this finding, it has been shown that some virulence genes in Salmonella typhimurium are activated within acidified phagosomes [11]. It has also been reported that the VirB secretion apparatus in Brucella is a kind of type IV secretion system. The acidification arising from phagosomes is a key intracellular signal that induces virB expression [12].
In response to stresses in host cells, several transcriptional regulators described in E. tarda can activate a series of interacting signaling networks [13]. Our previous study found that Eha is a transcriptional regulator of the MarR family [14]. Eha could also regulate the mRNA levels of some surface structures like the type III secretion system to affect the intracellular survival and virulence of E. tarda [15]. We found that Eha is required for the bacteria to resist oxidative stress and survive in macrophages [16]. As the type III secretion system in $E$. tarda disturbs the formation of the acidic environment in phagosomes [9], we hypothesized that Eha may be required for the bacteria to resist the acid stress in macrophages.

Next generation sequencing technology, RNA-Sequencing (RNAseq), has been used in bacterial transcriptome analyses [17]. We performed a high-throughput RNA-seq study, which has firstly been applied in the transcriptome analyses of $E$. tarda, to detect and compare the differentially-expressed genes (DEGs) between the ET13 wild type bacterium and its eha mutant following exposure to acid stress. Our present study provides the gene expression profiles and sheds light on the molecular mechanism by which $E$. tarda survival is regulated by Eha under acid stress conditions.

*Corresponding author: Daqing G, Department of Pathogenic Microbiology and Immunology, Southeast University School of Medicine, Nanjing, China, Tel: 086025-83272506; E-mail: dgao2@seu.edu.cn

Received September 05, 2017; Accepted September 26, 2017; Published September 30, 2017

Citation: Gao D, Liu N, Li Y, Zhang Y, Liu G, et al. (2017) Deep Sequencing Analysis of the Eha-Regulated Transcriptome of Edwardsiella tarda Following Acidification. Metabolomics (Los Angel) 7: 196. doi:10.4172/2153-0769.1000196

Copyright: (c) 2017 Gao D, et al. This is an open-access article distributed unde the terms of the Creative Commons Attribution License, which permits unrestricted use, distribution, and reproduction in any medium, provided the original author and source are credited. 


\section{Materials and Methods}

\section{Bacterial strains, plasmids, growth conditions and cell culture}

The ET13 wild type strain of E. tarda was provided by Dr. Janda [18] (California Department of Health Services Microbial Diseases Laboratory). The eha mutant strain and the complemented strain, ehaComp were constructed previously [14]. The pMP220 plasmid [19] was kindly provided by Prof. Mao (Department of Biochemistry, Southeast University). The eha gene was deleted from ET13 using the pHM5 suicide plasmid with homologous recombination to get the eha mutant strain. The complemented strain, ehaComp (the eha mutant containing plasmid pACYC184-eha), was constructed previously [14]. The pMP220-lac Z plasmid was kindly provided by Prof. Mao (Department of Biochemistry, Southeast University). Bacteria were grown in Luria-Bertani (LB) broth (Sunshine Biotechnology, Nanjing, China).

Murine RAW264.7 macrophages were obtained from Research Institute of Beijing Chuanglian North Carolina Biotechnology (Shanghai, China) and cultivated at $37^{\circ} \mathrm{C}$ in a $5 \% \mathrm{CO}_{2}$ incubator. The cell medium was Dulbecco's minimal essential medium (DMEM) (Gibco, Shanghai, China) containing 10\% fetal calf serum (FCS) (Gibco, Shanghai, China).

\section{Bacterial survival and replication in bafilomycin-treated macrophages}

The assay was performed according to the method reported by Gao [16]. Briefly, RAW264.7 macrophages were seeded at approximately $5.0 \times 10^{5}$ cells per well in 24-well tissue culture plates and incubated overnight. The cells in experimental groups were pretreated with $1 \mu \mathrm{M}$ bafilomycin (BAF) A1 for $30 \mathrm{~min}$, and the cells in the control groups were cultured without the inhibitor. Then the cells were infected for $1 \mathrm{~h}$ with the mid-log wild-type or mutant bacteria at a multiplicity of infection (MOI) of 10:1. The cells were incubated in DMEM medium containing gentamicin $(100 \mu \mathrm{g} / \mathrm{ml})$ for $1 \mathrm{~h}$ to kill the exocellular bacteria. After designated time intervals $(2,4,6 \mathrm{~h})$ post-infection, the macrophages were lysed with $1 \%$ Triton X-100 for 10 min, then the solutes were diluted, spread onto LB agar plates, and the plates were incubated at $37^{\circ} \mathrm{C}$ overnight. The numbers of the colony-forming units (cfu) per milliliter of viable intracellular bacteria on the plates were counted.

\section{Measurement of the intraphagosomal $\mathrm{pH}$ in $E$. tarda- containing macrophages}

The phagosome acidification assay was performed according to the manufacturer's instructions (SunShineBio, Nanjing, China) and was modified as described previously [20]. First, RAW264.7 cells were incubated with the mid-log wild-type or mutant bacteria at a multiplicity of infection (MOI) of 10:1. These were then labeled with FITC (SunShineBio, Nanjin, China) (pH-sensitive) and iFluorTM647 (AAT Bioquest, USA) ( $\mathrm{pH}$-insensitive) fluorescent dyes for $2 \mathrm{~h}$. The cells were washed twice and permeabilized in ice-cold Dulbecco's phosphate- buffered saline at a fixed $\mathrm{pH}$ (ranging from 3 to 8 ) in buffers comprising (DPBS)/ ethylenediaminetetraacetic acid containing $0.05 \%$ Triton X-100 in order to calculate the $\mathrm{pH}$ of E. tarda-containing vacuoles. The samples were immediately analyzed by flow cytometry to determine the ratio of the mean fluorescence intensity (MFI) of the emission between FITC and iFluorTM Fluor 647. A standard curve was made on the basis of the MFI for different $\mathrm{pH}$ in the phagosomes. Second, the cells in experimental groups were pretreated with $1 \mu \mathrm{M}$ bafilomycin (BAF) A1 for 30 min, while the cells in the control groups were cultured without the inhibitor. After the cells were infected by the bacteria and labeled with the fluorescent dyes, they were washed twice in DPBS buffer without Triton X-100. The values were compared with the standard curve generated from the cells that had phagocytosed $E$. tarda for different time periods $(2 \mathrm{~h}, 4 \mathrm{~h}, 6 \mathrm{~h})$ before the flow cytometry analysis.

\section{Recombinant plasmid construction and bacterial electrotransformation}

The forward primer: CAGATCTAATGGGTGAACCACGCAAAT and reverse primer: CTCTAGAATCCATAACCCCGATACACC were used to amplify a 358bp fragment from ET13 modified using BglII and XbaI. To construct the pMPE (pMP220-PehalacZ) plasmid, the 358bp eha promoter was inserted into pMP220-LacZ at BglII and XbaI sites. Inserted fragments from the pMPE plasmid were sent to the Sunshine Biotechnology Company for sequencing (Sunshine Biotechnology, Nanjing, China).

The pMPE plasmid was introduced into the eha mutant by electrotransformation [21]. Oxytetracycline plates $(50 \mu \mathrm{g} / \mathrm{ml})$ were used to screen for transformants (EHAMPE).

\section{$\beta$-Galactosidase assay}

The $\beta$-galactosidase assay was performed according to the product instructions (Sigma, Shanghai, China) and was modified as described by Sun [22]. The first modification place was that the $\beta$-galactosidase standard curve was made on the basis of the concentration of a $\beta$-galactosidase standard $(\mathrm{pg} / \mathrm{ml})$ and the absorbance at $420 \mathrm{~nm}$. Second, after the EHAMPE transformants were cultured in LB $(\mathrm{pH}=7.2)$ to an OD600 of 0.8 , the bacteria were treated with $\mathrm{LB}(\mathrm{pH}=6)$ for different periods of time $(0,1,2,3,4 \mathrm{~h})$, or at different $\mathrm{pH}(7.2,6.7$, $6.3,5.9,5.5,5.1,4.8,4.3,3.9) \mathrm{LB}$ for $2 \mathrm{~h}$, or the bacteria were treated with $0.5 \% \mathrm{H}_{2} \mathrm{O}_{2}$ of LB for different periods of time $(0,2,4,6 \mathrm{~h})$, or at different concentrations $(0.05 \%, 0.1 \%, 0.5 \%, 1 \%, 2 \%, 4 \%, 8 \%) \mathrm{H}_{2} \mathrm{O}_{2}$ of $\mathrm{LB}$ for $2 \mathrm{~h}$

\section{Bacterial growth, RNA isolation and mRNA enrichment}

After the wild type ET13 and its eha mutant were cultured in LB $(\mathrm{pH}=7.2)$ to an $\mathrm{OD} 600$ of 0.8 at $37^{\circ} \mathrm{C}$, these bacteria were treated with $\mathrm{LB}(\mathrm{pH}=6.3)$ for $2 \mathrm{~h}$. Total RNA was isolated from the bacteria using a RNA extraction kit (TaKaRa company, Dalian, China). The purity, integrity and RIN (RNA Integrity Number) of the RNA were assessed using an Agilent Bioanalzyer. The bacterial mRNA was enriched by the removal of $16 \mathrm{~S}$ and $23 \mathrm{~S}$ rRNA from the total RNA by poly-Toligoattached magnetic beads using a Microb Express Bacterial mRNA Enrichment Kit (Ambion, Shanghai, China).

\section{cDNA library construction and sequencing using the Illumina genome analyzer}

Complementary DNA (cDNA) libraries were built as described previously [23]. Briefly, the mRNA in each sample was fragmented into short sequences with divalent cations by heating in a proprietary buffer. Using the short fragments as templates, the first-strand cDNA was synthesized with random hexamer primers and reverse transcriptase (Invitrogen, Shanghai, China). The second-strand DNA was synthesized using RNase $\mathrm{H}$ and DNA polymerase I (Invitrogen, Shanghai, China). The amplified fragments were purified with a Qia Quick PCR Purification kit (Qiagen, Hilden, Germany), and poly (A) was added using Illumina PCR Primer Cocktail in a 35-cycle PCR. Two samples were sent to Shenzhen Hua Da Gene Company and sequenced using the Illumina sequencing 2000 platform. All sequences were 
Citation: Gao D, Liu N, Li Y, Zhang Y, Liu G, et al. (2017) Deep Sequencing Analysis of the Eha-Regulated Transcriptome of Edwardsiella tarda Following Acidification. Metabolomics (Los Angel) 7: 196. doi:10.4172/2153-0769.1000196

Page 3 of 10

examined for possible sequencing errors. Clean reads were obtained by removing the raw reads containing adapter, poly- $\mathrm{N}$, and any lowquality results. The RNA-seq data have been deposited in the National Center for Biotechnology Information-Sequence Read Achieve under accession number SRX1898774.

\section{RNA-seq alignment and identification of the eha-dependent genes altered by acid stress}

The clean reads were mapped onto the genome sequences of $E$. tarda ATCC15947 (http://www.ncbi.nlm.nih.gov/nuccore/) to reflect the distribution and coverage of the reads in the reference genome using the Short Oligonucleotide Analysis Package (SOAP). The gene expression of the two samples (wild type ET13 and its eha mutant) was quantified using the Reads Per Kilobase of coding sequence per Million reads (RPKM) algorithm. The genes were considered to be differentially expressed if the difference in RPKM values between the two samples was $\geq 2.0$-fold and the $p$-value was $<0.005$. The $p$-value was adjusted by the false discovery rate (FDR).

The Gene Ontology (GO) is an international standardized gene function classification system that is widely used to classify orthologous proteins. GO annotations for all possible eha-dependent genes were obtained from the GO database (http://www.geneontology.org/). The Kyoto Encyclopedia of Genes and Genomes (KEGG) is the major public pathway-related database that is used to identify significantly enriched metabolic pathways or signal transduction pathways (http:// www.genome.jp/kegg/).

\section{qRT-PCR}

The wild type ET13 and its eha mutant were cultured in the condition just like preparing RNA-seq. Total RNA was isolated from the bacteria using a RNA extraction kit (TaKaRa company, Dalian, China). The primers shown in Table 1 were used for quantitative realtime PCR (qRT-PCR). Using a SYBR ExScript qRT-PCR kit (Takara, Dalian, China), qRT-PCR was performed in an ABI 7300 real-time detection system (Applied Biosystems Company, USA). Bacterial 16S rRNA was used as a control. The $2-\Delta \Delta C T$ method [24] was used to compare the mRNA levels in wild type and mutant bacteria.

\section{Statistical analysis}

Probability $(\mathrm{P})$ values were determined by Student's t-test, and analyses were performed using the GraphPad Prism (version 6) software. The P values were considered to be significant when they were $<0.05$. The data for qRT-PCR were analyzed statistically by using twotailed t-tests. Pearson's correlation was used to evaluate the relationship between the results of qRT-PCR and RNA-seq, and was determined using SPSS. The difference was considered to be strong and significant when the correlation coefficient was $>0.75$; a moderate correlation was considered to be present when the coefficient was $<0.75$ and $>0.45$.

\section{Results}

\section{Identification of the conditions leading to the highest Eha activities in $\mathrm{EHA}_{\mathrm{MPE}}$ transformants}

To determine under what conditions the EHAMPE expresses the strongest Eha activities, we examined the $\beta$-galactosidase activity (regulated by Eha) of these EHAMPE transformants. Our results showed that the highest $\beta$-galactosidase activity was observed after $2 \mathrm{~h}$ exposure, when the transformants treated with $\mathrm{LB}(\mathrm{pH}=6.0)$ for different time (Figure 1A). Our results also found that the highest $\beta$-galactosidase activity was present at $\mathrm{pH}=6.3$ after $2 \mathrm{~h}$ exposure

\begin{tabular}{|c|c|c|c|}
\hline Gene Name & Primer Sequence $\left(5^{\prime} \rightarrow 3^{\prime}\right)$ & $\begin{array}{c}\text { Product } \\
\text { (bp) }\end{array}$ & $\begin{array}{l}\text { Annealing } \\
\mathrm{T}\left({ }^{\circ} \mathrm{C}\right)\end{array}$ \\
\hline \multicolumn{4}{|l|}{ Up-regulated } \\
\hline ETATCC_RS01560 & $\begin{array}{l}\text { GCCAGCACAGGTGATCTCGG } \\
\text { CGAGGATACGGACATGAGCC }\end{array}$ & 134 & 59.50 \\
\hline ETATCC_RS01555 & $\begin{array}{l}\text { TGGAGCCATTATCACTTTCG } \\
\text { CGATCTGCGCTAATACCTCC }\end{array}$ & 154 & 57.45 \\
\hline ETATCC_RS05005 & $\begin{array}{l}\text { TGGGCGTCGGTGCCTTCTTC } \\
\text { GCCATCGCCAACAGGAATAG }\end{array}$ & 166 & 57.55 \\
\hline ETATCC_RS11570 & $\begin{array}{l}\text { CTATCGCCAAACCCATTACC } \\
\text { TCGTCACCGACTACAAACCA }\end{array}$ & 141 & 55.40 \\
\hline ETATCC_RS13205 & $\begin{array}{l}\text { TTCCTGCGGCACAGTTGAA } \\
\text { GGCATTGGCTGATTGGTTG }\end{array}$ & 190 & 58.00 \\
\hline ETATCC_RS14200 & $\begin{array}{l}\text { TCTTCCAGCAGGGATTCGG } \\
\text { GCTGGTCTTGGCTACCGTCA }\end{array}$ & 147 & 59.50 \\
\hline ETATCC_RS11220 & $\begin{array}{l}\text { GGTGGACGAGGCGTTCCTT } \\
\text { CAATAGCGGCAGCGACAGC }\end{array}$ & 172 & 62.00 \\
\hline ETATCC_RS10525 & $\begin{array}{l}\text { CATTGGTGCGCCTGGAAGA } \\
\text { ACACGCCGATGGTGAACGT }\end{array}$ & 168 & 60.00 \\
\hline ETATCC_RS09485 & $\begin{array}{l}\text { TGGCGCTAGTGCAAGAACA } \\
\text { TACGGCATGGATGCTGACC }\end{array}$ & 155 & 58.00 \\
\hline ETATCC_RS14205 & $\begin{array}{l}\text { GCCATCTGGATCGGTAACTT } \\
\text { CATCTCCTGCACATTGACGT }\end{array}$ & 168 & 55.40 \\
\hline \multicolumn{4}{|l|}{ Down-regulated } \\
\hline ETATCC_RS16120 & $\begin{array}{l}\text { TAGCTGATCCAGCGTCCTG } \\
\text { GCGTTTGAAGCCGTTAGAG }\end{array}$ & 145 & 58.00 \\
\hline ETATCC_RS06155 & $\begin{array}{l}\text { ACTTTGCCGTGTTTGTCGC } \\
\text { GCAGGGTTGAACAGCAGGA }\end{array}$ & 124 & 58.00 \\
\hline ETATCC_RS11420 & $\begin{array}{l}\text { TTGGATCTGGAGAAGGGTG } \\
\text { CTGCAATGTTGTCGAGGAGT }\end{array}$ & 142 & 58.00 \\
\hline ETATCC_RS00925 & $\begin{array}{l}\text { TGACCGTGCGTGGTAATCC } \\
\text { GCGGCTGTAGTGCTTCTGG }\end{array}$ & 186 & 60.00 \\
\hline ETATCC_RS10185 & $\begin{array}{l}\text { AACTTGGTCGGTTGGGATG } \\
\text { GCTGTGACGGGAGTTAGGC }\end{array}$ & 120 & 59.45 \\
\hline
\end{tabular}

Table 1: The primer sequences, product sizes and annealing temperatures for RT-qPCR.

(Figure 1B), when the transformants treated with different $\mathrm{pH}$ of LB. At the same time, our results showed that the highest $\beta$-galactosidase activity was observed after for $2 \mathrm{~h}$ exposure, when the transformants treated with $0.5 \% \mathrm{H}_{2} \mathrm{O}_{2}$ of $\mathrm{LB}$ for different time (Figure 1C). Our results also found that the highest $\beta$-galactosidase activity was present to $0.1 \%$ $\mathrm{H}_{2} \mathrm{O}_{2}$ of $\mathrm{LB}$ after $2 \mathrm{~h}$ exposure, when the transformants treated with different concentration of $\mathrm{H}_{2} \mathrm{O}_{2}$ of $\mathrm{LB}$ (Figure 1D). Finally, we decided to select the condition was $\mathrm{LB}(\mathrm{pH}=6.3)$ for $2 \mathrm{~h}$ (Figure 1E).

\section{Evaluation of the transcriptomes of the wild type and eta mutant bacteria}

The RNA concentrations isolated from wild type ET13 and its eha mutant were 1.905 and $1.255 \mu \mathrm{g} / \mu \mathrm{l}$, respectively. Their purities were OD260/OD280 $\geq 1.9$ and OD260/OD230 $\geq 2.0$, RIN:10.0. The two kinds of RNA were considered to be of sufficient quality to construct a cDNA library (Table 1S).

Illumina sequencing of the wild type and mutant bacteria cultured under acid stress generated raw reads per library, respectively. After filtration to remove the low-quality reads, a total of 12,233,396 (wild type) and 12,122,800 (mutant) clean reads were separately obtained from the raw reads of the two samples. More than $94 \%$ of the clean reads of 11501727 (94.02\%) for wild type and 11443179 (94.39\%) for mutant completely matched the reference genome of E. tarda ATCC15947. Among the clean reads, there were 7233093 (59.13\%; wild type) and 6313604 (51.48\%; mutant) perfect matches, and 4268634 (34.89\%; wild type) and (34.91\%; mutant) had a $\leq 5$ bp mismatch (Table 2 S). 
A

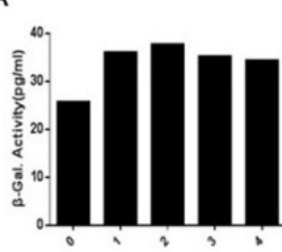

Length of exposure to $\mathrm{pH} 6$ medium(h)

C

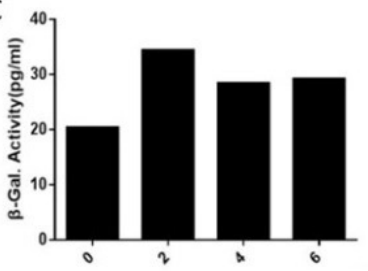

Length of exposure to $0.5 \% \mathrm{H}_{2} \mathrm{O}_{2}$ medium (h)
B

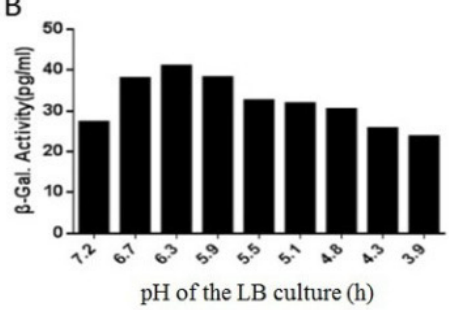

D

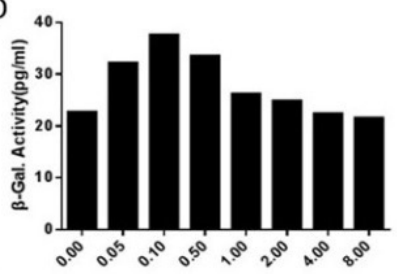

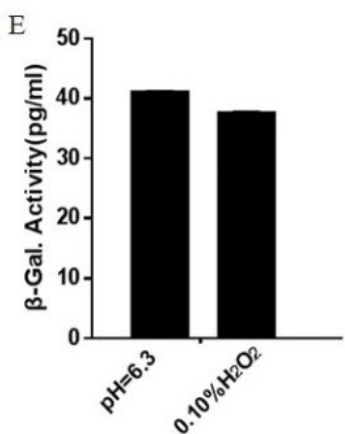

$\mathrm{pH}$ or $\mathrm{H}_{2} \mathrm{O}_{2}$ of the $\mathrm{LB}$ culture

$\mathrm{H}_{2} \mathrm{O}_{2}$ of the LB culture

Figure 1: The $\beta$-galactosidase activities of EHAMPE transformants in different cultural conditions. The $\beta$-galactosidase activities of the eha mutant strains carry plasmid pMPE (pMP220-PehalacZ) have been tested. The plasmids encode either eha gene promoter or lacZ gene. The transformant strains were treated with LB $(\mathrm{pH}=6)$ for various length of time $(0,1,2,3,4 \mathrm{~h})(\mathrm{A})$, or with $\mathrm{LB}$ at different $\mathrm{pH}(7.2,6.7,6.3,5.9,5.5,5.1,4.8,4.3,3.9)$ for $2 \mathrm{~h}(\mathrm{~B})$, or with $0.5 \% \mathrm{H} \mathrm{O}_{2}$ concentration of LB for different periods of time $(0,2,4,6 \mathrm{~h})(\mathrm{C})$, or at different concentrations $(0.05 \%, 0.1 \%, 0.5 \%, 1 \%, 1 \%, 2 \%, 4 \%, 8 \%) \mathrm{H}_{2} \mathrm{O}_{2}$ of $\mathrm{LB}$ for $2 \mathrm{~h}(\mathrm{D})$. The $\beta$-galactosidase activities of the transformant strains treated with $\mathrm{LB}(\mathrm{pH}=6)$ were compared with those with $\mathrm{LB}\left(0.1 \% \mathrm{H}_{2} \mathrm{O}_{2}\right)(\mathrm{E})$. The error bars represented the SD of three parallel experiments.

It is important to annotate sequences, because it can reveal the molecular mechanisms underlying changes in gene expression. Using the SOAP software to assess the randomness and coverage of the clean reads mapped to the reference genome, our results showed that different sizes of clean reads were well-distributed in the reference genome (Figure 1S) and the degree of coverage for more than $90 \%$ of the clean reads exceeded $92 \%$ of the reference genome (Figure $2 \mathrm{~S}$ ).

\section{Functional classification of the eha-dependent genes}

We quantified the transcriptional activity of the genes using the RPKM algorithm. By comparing the expression levels of the eha mutant with the wild type bacteria, we found that 147 genes were significantly differentially transcribed between the two samples under acid stress $(\mid \log 2$ ratio $\mid \geq 1, F D R \leq 0.001$, and q value $<0.005)$. Among these genes, 113 were up-regulated and 34 were down-regulated in the eha mutant, compared with the wild type.

Functional assignments were defined by Gene GO terms, which provided a broad functional classification of the genes and their products. A GO category analysis revealed that 126 among the 147 genes were classified into 25 functional categories. These genes were mainly involved in binding (59 genes), catalytic activity (83 genes), cell components (37 genes), cell membranes (33 genes), cellular processes (68 genes), localization ( 30 genes), metabolism ( 78 genes), and transport (27 genes) (Figure 2). These were considered to be genes that were transcribed in an eha-dependent manner in response to acid stress.

\section{Pathway analysis of the eha-dependent genes}

To further investigate the biological functions and interactions of these genes, a pathway-based analysis was conducted using the KEGG pathway database, which contains all known networks of molecular interactions in different species. The KEGG analysis showed that 130 of the 147 total DEGs were associated with 55 pathways, including amino acid metabolism (10 pathways); carbohydrate, lipid and energy

\begin{tabular}{|c|c|c|c|c|c|} 
Sample & $\begin{array}{c}\text { concentration } \\
\text { (ng/ } \mathbf{\mu l})\end{array}$ & $\mathbf{O D}_{\mathbf{2 6 0 / 2 8 0}}$ & $\mathbf{O D}_{\mathbf{2 6 0 / 2 3 0}}$ & $\mathbf{R I N}$ & $\mathbf{2 3 S / 1 6 S}$ \\
\hline wild type & 1905 & 2.03 & 2.33 & 10 & 1.3 \\
\hline eha mutant & 1255 & 1.99 & 2.29 & 10 & 1.2 \\
\hline
\end{tabular}

Table 1S: The RNA qualities of the wild type and eha mutant ET13.

\begin{tabular}{|c|c|c|}
\hline & Wild type ET13 & eha mutant ET13 \\
\hline Total Reads & $12233396(100.00 \%)$ & $12122800(100.00 \%)$ \\
\hline Total Base Pairs & $1101005640(100.00 \%)$ & $1091052000(100.00 \%)$ \\
\hline Total Mapped Reads & $11501727(94.02 \%)$ & $11443179(94.39 \%)$ \\
\hline Perfect match & $7233093(59.13 \%)$ & $7210872(59.48 \%)$ \\
\hline$\leq 5$ bp mismatch & $4268634(34.89 \%)$ & $4232307(34.91 \%)$ \\
\hline
\end{tabular}

Table 2S: The numbers (percentages) of clean reads for the wild type and eha mutant ET13 from Map to Genome.

metabolism (16 pathways); nucleotide metabolism (four pathways); sulfur metabolism (three pathways); nitrogen metabolism; iron transport and so on. The pathway analysis may help to understand the interactions among these genes. The metabolic pathways of the DEGs were involved in two-component systems (20 genes), ABC transporters (12 genes), microbial metabolism in diverse environments (21 genes), biosynthesis of secondary metabolites (17 genes) and flagellar assembly (3 genes) (Table 2).

\section{Validation of RNA-seq analysis by qRT-PCR}

It is common practice to validate the DEGs found by the RNAseq using another method, such as qRT-PCR. We therefore compared the qRT-PCR expression levels of 15 genes randomly selected from the wild type and mutant bacteria. The mean values of the $\log 2$ ratio of the eha mutant to the wild type determined by qRT-PCR were in good agreement with the $\log 2$ ratios of the eha mutant to the wild type from the RNA-seq analysis for 14 of the 15 genes (Figure 3), with a significant correlation noted for these genes $(\mathrm{R} 2=0.799>0.75)$. There was only one exception (ETATCC -RS11570), therefore, the data from the qRT-PCR analysis validated the findings from the RNA-seq analysis. 
Citation: Gao D, Liu N, Li Y, Zhang Y, Liu G, et al. (2017) Deep Sequencing Analysis of the Eha-Regulated Transcriptome of Edwardsiella tarda Following Acidification. Metabolomics (Los Angel) 7: 196. doi:10.4172/2153-0769.1000196

A

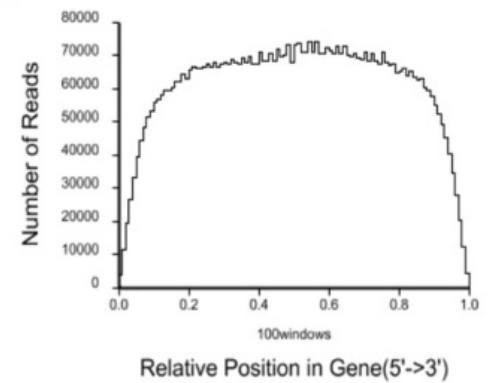

B

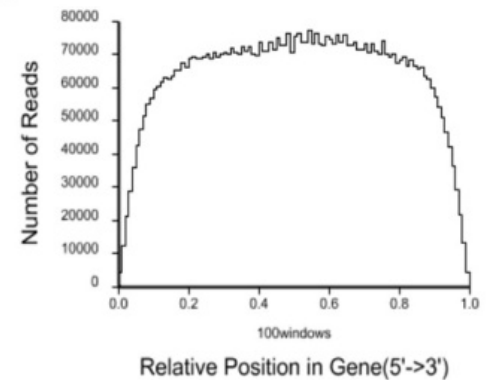

Figure 1S: The randomness assessment of the clean reads of the eha mutant and its wild type ET13 mapped to the reference genome. The results showed that there were different sizes for the clean reads of the eha mutant (A) and the wild type ET13 (B) which were distributed in the reference genome of $E$. tarda ATCC15947.

A

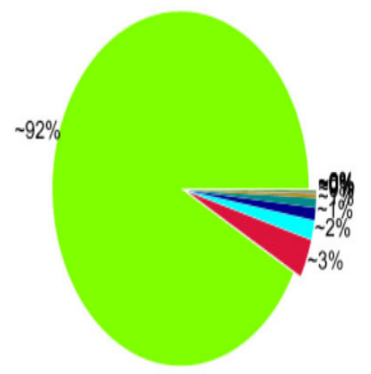

B

$90 \%-100 \%(2761)$
$80 \%-80 \%(104)$
$70 \%-80 \%(52)$
$60 \%-70 \%(33)$
$50 \%-60 \%(26)$
$40 \%-50 \%(10)$
$30 \%-40 \%(5)$
$20 \%-30 \%(4)$
$10 \%-20 \%(2)$
$0 \%-10 \%(0)$

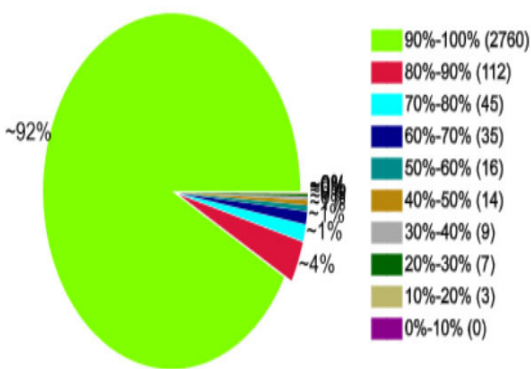

Figure 2S: The coverage statistics of the clean reads of the eha mutant and the wild type ET13 bacteria mapped to the reference genome. The results showed that the coverage of the eha mutant (A) and the wild type ET13 (B) in over $90 \%$ of the clean reads exceeded $92 \%$ of the reference genome of $E$. tarda ATCC15947.

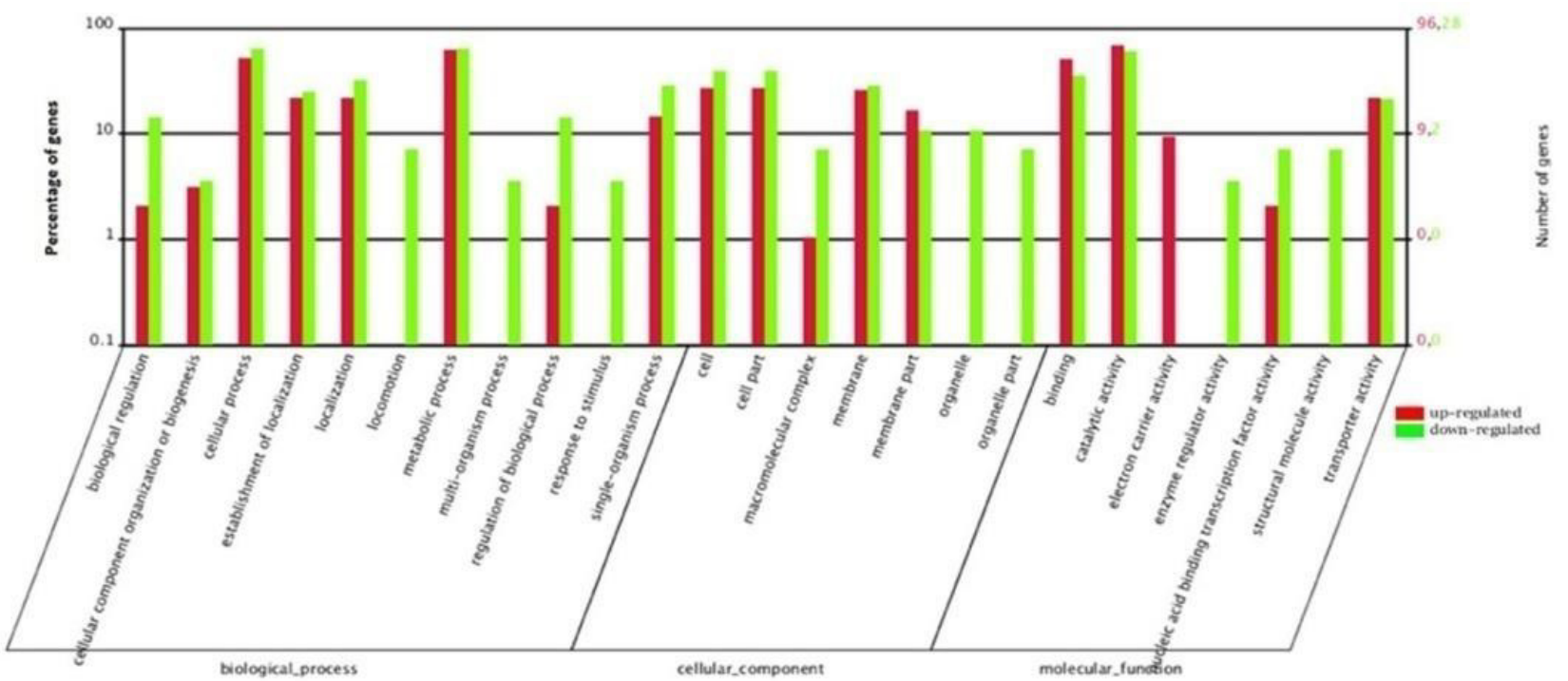

Figure 2: The numbers and functional categories of the DEGs between the wild type and eha mutant ET13.

There were 147 DEGs in the eha mutant compared with the wild type bacteria (|log2 ratio| $\geq 1)$. The functional categories of these genes shown were up-regulated (red color) and down-regulated (green color) by Eha in ET13 bacteria subjected to acid stress.

\section{Eha expression provides $E$. tarda with a survival advantage}

Our previous studies have shown that ET13 can survive within macrophages for extended periods of time [16]. It has been indicated that the acidification of phagosomes containing Yersinia pseudotuberculosis in macrophages can be blocked by BAF A1, a vacuolar proton-ATPase pump inhibitor [25]. To better characterize the persistence of ET13 against acidification in macrophages and to follow the fate of the internalized bacteria after BAF A1 was used to block acidification, we first accurately monitored the survival rate of ET13 in the cells beginning the second hour post-infection by cell lysis and plate counting. As controls, other cells were cultured without the inhibitor. The pretreatment had 
Citation: Gao D, Liu N, Li Y, Zhang Y, Liu G, et al. (2017) Deep Sequencing Analysis of the Eha-Regulated Transcriptome of Edwardsiella tarda Following Acidification. Metabolomics (Los Angel) 7: 196. doi:10.4172/2153-0769.1000196

Page 6 of 10

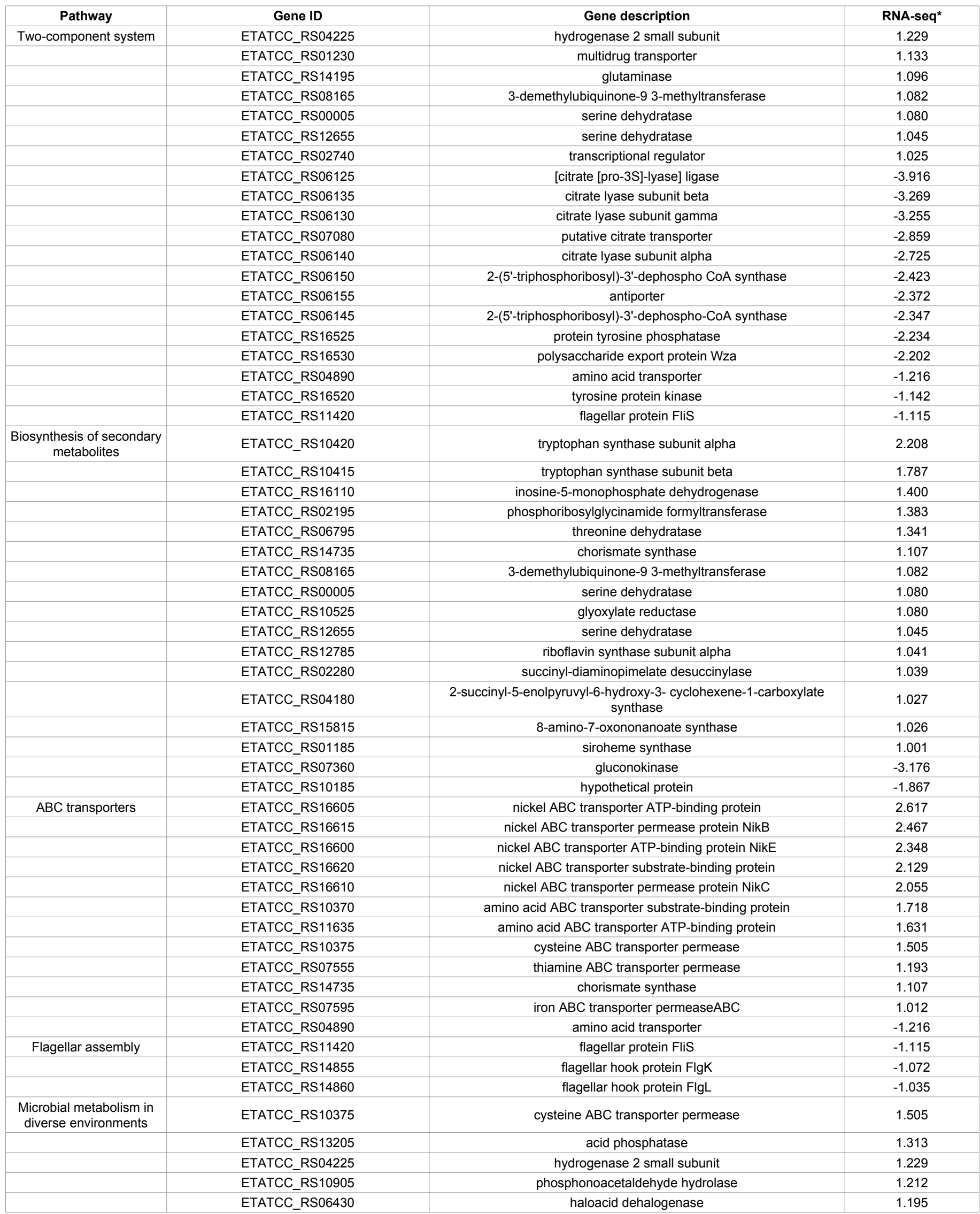




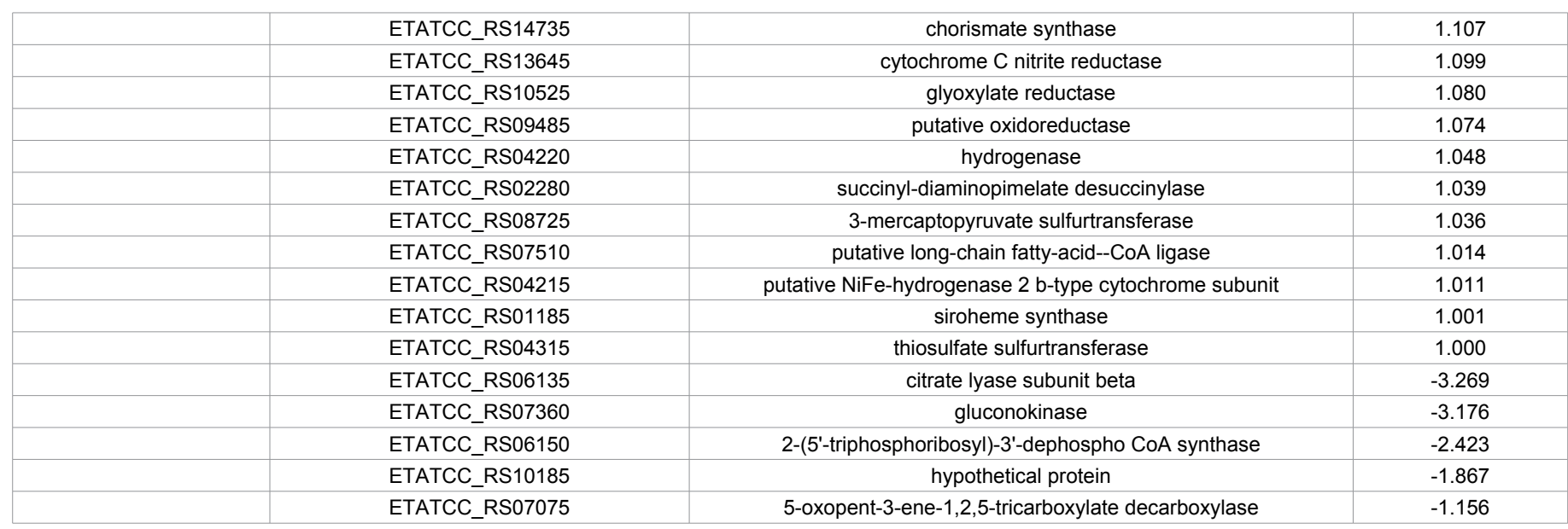

RNA-seq*: $\quad$ log2 Ratio(eha_mutant_ET13/wild_ET13)I $\geq 1.00$

Table 2: The results of the KEGG pathway analysis of the eha-dependent genes differentially expressed under acid conditions.

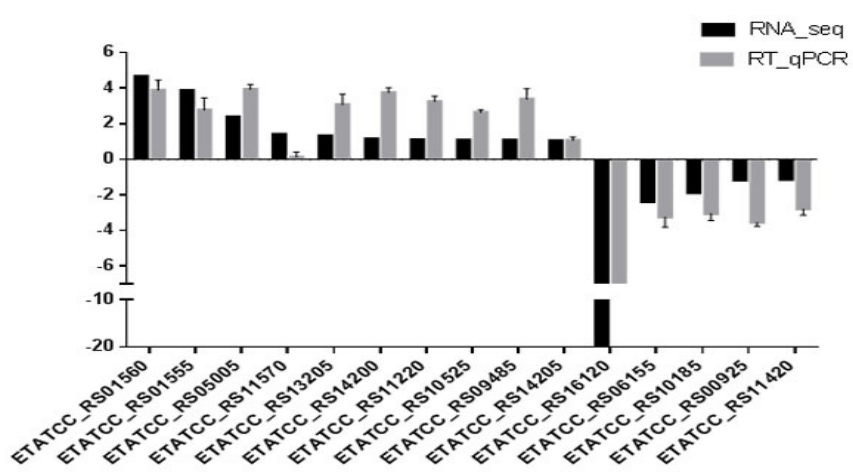

Figure 3: Validation of the RNA-seq data using RT-q PCR. Fifteen representative genes were chosen to validate the RNA-seq data by RT-qPCR. The gray bars represent the mean values of the log2 ratios of the eha mutant to the wild type obtained from three RT-qPCR experiments, and the error bars represent the standard deviation (SD) of three parallel experiments, and the black bars represent the log2 ratio of the eha mutant to the wild type by RNA-seq data.

no observable deleterious effects at the early time points $(2 \mathrm{~h})$. However, after four or six hours, the numbers of wild type and mutant bacteria recovered from BAF-treated macrophages were higher than those for the untreated cells $(\mathrm{P}<0.05)($ Figure $4 \mathrm{~A})$. To more precisely determine the $\mathrm{pH}$ of the lumen of $E$. tarda-containing vacuoles, we employed a ratiometric assay in which Alexa Fluor 647/FITC-labelled E. tarda was used as a $\mathrm{pH}$-sensitive probe. The $\mathrm{pH}$ in vacuoles containing the wild type or mutant recovered from BAF-treated macrophages was higher than that for the untreated cells at $2 \mathrm{~h}, 4 \mathrm{~h}$ and $6 \mathrm{~h}$ post-infection $(\mathrm{P}<0.05)$ (Figure 4B). These results showed that acidification is important for inhibiting the survival and replication of E. tarda in macrophages.

Second, we wanted to better explain how Eha regulates the resistance of E. tarda against acidification in macrophages and to compare the fates of the internalized wild type and mutant bacteria. The CFU of the wild type bacteria in untreated macrophages was higher than that of the mutant at $4 \mathrm{~h}$ and $6 \mathrm{~h}$ post-infection $(\mathrm{P}<0.05)$ (Figure $4 \mathrm{~A})$. Moreover, at the later time points $(4 \mathrm{~h}, 6 \mathrm{~h})$, there were no differences in the $\mathrm{pH}$ of vacuoles containing the wild type and mutant bacteria in untreated macrophages $(\mathrm{P}>0.05)$ (Figure $4 \mathrm{~B})$. Therefore, Eha may be involved in protecting the bacteria against the effects of acidification.

\section{The eha mutants exhibited decreased survival under acidic conditions}

The in vitro bacterial survival rates were observed after the bacteria were treated with different $\mathrm{pH}(7.2,6.3,5.5,4.8,4.3) \mathrm{LB}$ for two hours. All strains (wild type, mutant and complemented) had reduced survival rates as the $\mathrm{pH}$ decreased (Figure 5). However, at the lower $\mathrm{pH}$ values $(6.3,5.5,4.8,4.3)$, the survival rates of the mutant were lower than those of the wild type bacteria $(\mathrm{P}<0.05)$. The survival rates of the complemented strains were between those of the wild type and mutant bacteria. These results suggest that the eha mutant was more susceptible to acid stress than the wild type bacteria, indicating that Eha is required for free-living ET13 to resist acid stress.

\section{Discussion}

In the present study, we examined under what conditions the EHAMPE expressed the strongest Eha activities. On the condition, we compared the whole transcriptomic profiles of the wild type ET13 and its eha mutant, and found 147 DEGs to adapt to acid stress. Moreover, our experiments showed that Eha was involved in protecting the bacteria against acid stress in vitro and against the effects of acidification in vivo.

To survive and adapt to their environment, bacteria integrate multiple signal conduction pathways, such as the two-component system (TCS), to mediate an appropriate cellular response [26]. Our study found that 20 genes that were differentially expressed between the ET13 wild type bacteria and eha mutant are involved in the TCS pathways, seven of which were down-regulated and 13 of which were up-regulated under acid stress. Most interestingly, these down- 


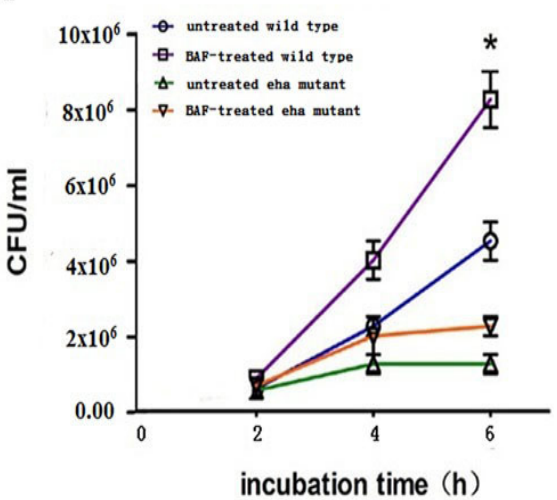

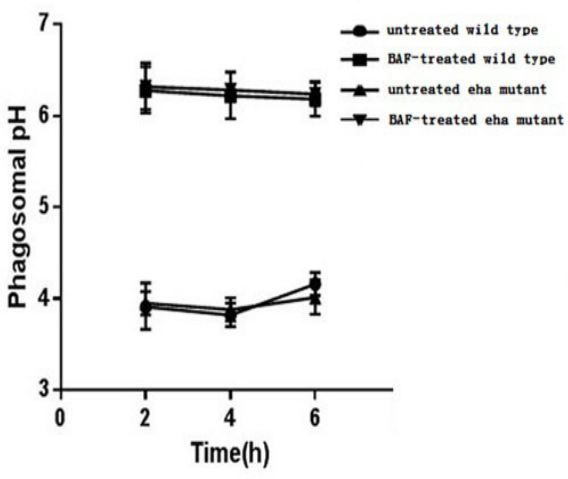

Figure 4: Eha provides $E$. tarda with a survival advantage against acidification in macrophages. BAF-treated and untreated RAW264.7 cells were infected with the wild type and eha mutant $E$. tarda strains for $2 \mathrm{~h}$ at a MOI of 10 , respectively. A. After designated time intervals $(2,4,6 \mathrm{~h})$ post-infection, the numbers of the colony-forming units (cfu) per milliliter of viable intracellular bacteria on the plates were counted. B. These cells were infected and labeled with FITC (pH-sensitive) and Alexa Fluor 647 ( $\mathrm{pH}$-insensitive) fluorescent dyes for $2 \mathrm{~h}$, then were analyzed by flow cytometry to determine the ratio of the MFI emission between FITC and Alexa Fluor 647 . Note : ${ }^{*} P<0.05$, considered to be statistically significant.

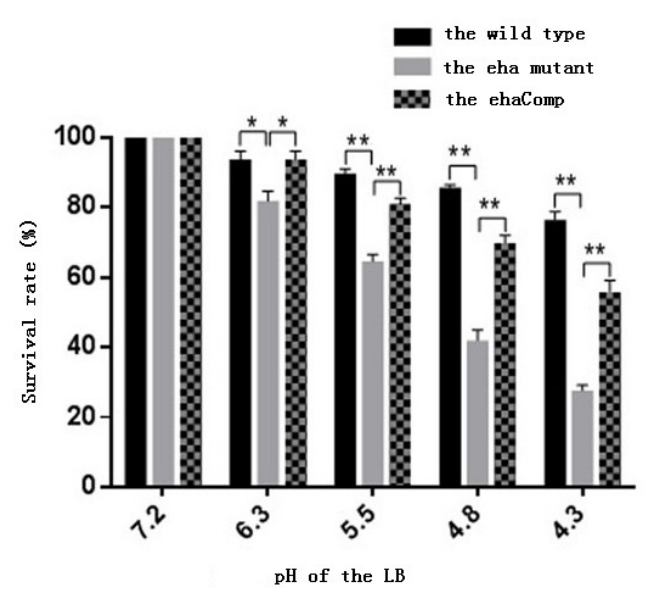

Figure 5: The survival of $E$. tarda after treatment with different $\mathrm{pH}$ medium. The bacterial survival rates are presented as the percentages of the numbers of colonies derived from acid-treated cells after the treatment with different $\mathrm{pH}(7.2,6.3,5.5,4.8,4.3) \mathrm{LB}$ for $2 \mathrm{~h}$ relative to untreated cells. $P$ values are shown for the groups compared, which represented the wild type, mutant or complemented strains. Note: ${ }^{\star} P<0.05$ and ${ }^{* *} P<0.01$, the difference was considered to be statistically significant.

regulated DEGs (ETATCC_RS06125, ETATCC_RS06135, ETATCC_ RS06130, ETATCC_RS07080, ETATCC_RS06140, ETATCC_ RS06155, ETATCC_RS06145 and ETATCC_RS06150) are all related to citric acid metabolism. The DEGs TATCC_RS06140, ETATCC_ RS06135 and ETATCC_RS06130 code for $\alpha, \beta$ and $\gamma$ subunits of citric acid lyase C. The DEGs ETATCC_RS06145 and ETATCC_ RS06150 encode citric acid lyase G subunits. Citric acid and its lyase are the intermediate product and critical enzyme of the tricarboxylic acid (TCA) cycle, respectively. The TCA cycle is critical for carbon metabolism and energy generation [27]. In a previous study, a lyase gene mutant $E$. tarda was unable to proliferate and cause fatal infection in a fish model [28].

The DEGs ETATCC_RS14195 code for glutaminase, and both ETATCC_ RS00005 and ETATCC_RS12655 code for serine dehydratases. Glutaminases in Helicobacter pylori deaminate glutamine to glutamate, resulting in the production of ammonia, which may be of significance in the pathogenesis of $\mathrm{H}$. pylori-associated diseases [29]. The gene ETATCC_RS06155 encodes and antiporter like a gastric proton pump. The pump in $H$. pylori is implicated in transient hypochlorhydria, which facilitates gastric colonization and potentially triggers the epithelial progression to neoplasia [30]. The ETATCC_ RS16530 gene codes for an outer membrane protein that transports capsule polysaccharides from the periplasmic space to the bacterial surface. Polysaccharides may serve to protect organisms from harsh environmental conditions and to increase their virulence [31].

Our present transcriptomic analysis also discovered that 17 of the DEGs were associated with the biosynthesis of secondary metabolites, and these were significantly up-regulated under acid stress. Secondary metabolites are synthesized using primary metabolites as precursors and regulators, and the process is easily affected by the bacterial environment [32]. ETATCC_ RS10420 and ETATCC_ RS10415 encode tryptophan synthases. The tryptophan synthases in Chlamydia trachomatis regulate the bacterial survival rates in Hela cells and the resistance to IFN- $\gamma$ [33]. ETATCC_RS06795 encodes threonine dehydratase. The threonine dehydratase in Streptococcus pneumoniae contributes to the bacterial virulence and colonization in pneumococcal infection [34]. The findings suggest that these DEGs may regulate the virulence and survival of $E$. tarda. 
Our transcriptomic analysis also found that Eha was associated with 12 up- regulated DEGs involved in $\mathrm{ABC}$ transporter systems, like oligopeptide permease (Opp) in the bacterial membrane that transports nickel, amino acids, thiamine, iron and so on [35]. Nickel enzymes have nickel in their active center, which is required for their biological function. Nickel enzymes include urease, hydrogenase, carbon monoxide dehydrogenase. The Opp1 ABC transporter in Staphylococcus aureus imports nickel and cobalt, and its mutant showed reduced mortality in terms of systemic infection and colonization of the bladder and kidneys in a urinary tract infection model [36]. Eha may regulate $\mathrm{ABC}$ transporter systems to control the entry of nickel and the other micronutrients into bacteria, and bacterial urease, hydrogenase and other nickel enzymes may affect the survival rates in different environments and may regulate the pathogenicity of $E$. tarda.

ETATCC_RS11420, ETATCC_RS14855, and ETATCC_ RS14860 encode FliS of the chaperone of flagellin FliC [37] and FlgK and FlgL of the flagellar hook, respectively [38]. The FlgM-FliA regulatory circuit plays a central role in coordinating bacterial flagellar assembly. FliS modulates FlgM activity as a chaperone to control late flagellar gene expression, motility and biofilm formation in Yersinia pseudotuberculosis [39]. A bacterial biofilm is a structured community of bacteria in a self-produced extracellular matrix, which allows the bacteria to adhere to a solid surface or biological tissue. The formation of biofilms apparently improves the ability of the bacteria to resist adverse environmental conditions.

Our RNA-seq analysis revealed that 20 of the DEGs, including ETATCC_ RS13205, are directly involved in bacterial metabolism under different circumstances, and participate in material synthesis and degradation, as well as energy metabolism networks. ETATCC_ RS13205 encodes an acid phosphatase, an enzyme which is associated with the synthesis of bacterial capsule I and IV, which takes part in bacterial resistance [40]. These findings are not only important to better understand the roles of the various DEGs in bacterial physiology, but will help to generally understand the full potential and evolution of protein phosphorylation for signal transduction, protein modification and homeostasis in all bacteria [41].

In summary, the high-throughput RNA-seq was used to examine the whole transcriptomic profile of E. tarda for the first time. Overall, we observed that Eha regulates 147 genes that affect the bacterial energy, metabolism, and virulence, which allow $E$. tarda to adapt to an acid environment. Therefore, these results could be helpful for further investigations of the molecule mechanism(s) underlying how $E$. tarda survive in macrophages under acidification.

\section{Acknowledgement}

The work was supported by the National Nature and Science Foundation of China (No. 31570124)

\section{References}

1. Mohanty BR, Sahoo PK (2007) Edwardsiellosis in fish: a brief review. J Biosci 32: $1331-1344$

2. Nelson JJ, Nelson CA, Carter JE (2009) Extraint estinal manifestations of Edwardsiella tarda infection: a 10-year retrospective review. J La State Med Soc 161: 103-106.

3. Zhang L, Ni C, Xu W, Dai T, Yang D, et al. (2016) Intramacrophage Infection Reinforces the Virulence of Edwardsiella tarda. J Bacteriol 198: 1534-1542.

4. Weiss G, Schaible UE (2015) Macroph age defense mechanisms against intracellular bacteria. Immunol Rev 264: 182-203.

5. Okuda J, Takeuchi Y, Nakai T (2014) Type II I secretion system genes of Edwardsiella tarda associated with intracellular replication and virulence in zebrafish. Dis Aquat Organ 111: 31-39.
6. Leung KY, Siame BA, Tenkink BJ, Noort RJ, Mok YK (2012) Edwardsiella tarda -virulence mechanisms of an emerging gastroenteritis pathogen. Microbes Infect 14: 26-34.

7. Srinivasa Rao PS, Yamada Y, Leung KY (2003) A major catalase (KatB) that is required for resistance to $\mathrm{H} 2 \mathrm{O} 2$ and phagocyte-mediated killing in Edwardsiella tarda. Microbiol 149: 2635-2644.

8. Cheng S, Zhang M, Sun L (2010) The iron-cofact ored superoxide dismutase of Edwardsiella tarda inhibits macrophage-mediated innate immune response. Fish Shellfish Immunol 29: 972-978.

9. Okuda J, Kiriyama M, Suzaki E, Kataoka K, Nishibuchi M, et al. (2009) Characterization of proteins secreted from a type III secretion system of Edwardsiella tarda and their roles in macrophage infection. Dis Aquat Organ 84: 115-121.

10. Rathman M, Sjaastad MD, Falkow S (1996) Acidification of phagosomes containing Salmonella typhimurium in murine macrophages. Infect Immun 64: 2765-2773.

11. Alpuche Aranda CM, Swanson JA, Loomis WP, Miller SI (1992) Salmonella typhimurium activates virulence gene transcription within acidified macrophage phagosomes. Proc Natl Acad Sci USA 89: 10079-10083.

12. Boschiroli ML, Ouahrani-Bettache S, Foulongne V, Michaux-Charachon S, Bourg G, et al. (2002) The Brucella suis virB operon is induced intracellularly in macrophages. Proc Natl Acad Sci USA 99: 1544-1549.

13. Chakraborty S, Sivaraman J, Leung KY, Mok YK (2011) Two-component PhoBPhoR regulatory system and ferric uptake regulator sense phosphate and iron to control virulence genes in type III and VI secretion systems of Edwardsiella tarda. J Biol Chem Nov 286: 39417-39430.

14. Gao D, Cheng J, Zheng E, Li Y, Shao Z, et al. (2014) Eha, a transcriptional regulator of hemolytic activity of Edwardsiella tarda. FEMS Microbiol Lett 353 132-140.

15. Gao D, Zhou X, Li Y, Xu Z, Sheng A, et al. (2016) The role of regulator Eha in Edwardsiella tarda pathogenesis and virulence gene transcription. Microbiol Pathogen 95: 216-223

16. Gao D, Li Y, Zheng E, Liu N, Shao Z, et al. (2016) Eha, a regulator of Edwardsiella tarda, required for resistance to oxidative stress in macrophages. FEMS Microbiol Lett 363.

17. Wang H, Lei $Y$, Yan L, Cheng K, Dai X, et al. (2015) Deep sequencing analysis of transcriptomes in Aspergillus flavus in response to resveratrol. BMC Microbiol 15: 182-196.

18. Janda JM, Abbott SL, Kroske-Bystrom S, Cheung WK, Powers C, et al. (1991) Pathogenic properties of Edwardsiella species. J Clin Microbiol 29: 1997-2001.

19. Nong G, Zhang Z, Hu F, Chen $H$ (1998) Cloning and analysis of the regulatory gene fragment induced with seed extract in Rhizobium huakuii strain $7653 \mathrm{R}$. Wei Sheng Wu Xue Bao 38: 225-228.

20. Sokolovska A, Becker CE, Ip WK, Rathinam VA, Brudner M, et al. (2013) Activation of caspase-1 by the NLRP3 inflammasome regulates the NADPH oxidase NOX2 to control phagosome function. Nat Immunol 14: 543-553.

21. Welker DL, Hughes JE, Steele JL, Broadbent JR (2015) High efficiency Electrotransformation of Lactobacillus casei. FEMS Microbiol Lett 362: 1-6.

22. Sun L, vanderSpek J, Murphy JR (1998) Isolation and characterization of ironindependent positive dominant mutants of the diphtheria toxin repressor DtxR. Proc Natl Acad Sci USA 95: 14985-14990.

23. Wang H, Lei $Y$, Yan L, Cheng K, Dai X, et al. (2015) Deep sequencing analysis of transcriptomes in Aspergillus flavus in response to resveratrol. BMC Microbiol 15: 182-196.

24. Livak KJ, Schmittgen TD (2001) Analysis of relative gene expression data using real-time quantitative PCR and the 2(-Delta Delta C(T)) Method. Methods 25: $402-408$.

25. Tsukano H, Kura F, Inoue S, Sato S, Izumiya H, et al. (1999) Yersinia pseudotuberculosis blocks the phagosomal acidification of B10. A mouse macrophages through the inhibition of vacuolar $\mathrm{H}(+)$-ATPase activity. Microb Pathog 27: 253-263.

26. Lv Y, Xiao J, Liu Q, Wu H, Zhang Y, et al. (2012) Systematic mutation analysis of two- component signal transduction systems reveals EsrA-EsrB and PhoP$\mathrm{PhoQ}$ as the major virulence regulators in Edwardsiella tarda. Vet Microbio 157: 190-199. 
Citation: Gao D, Liu N, Li Y, Zhang Y, Liu G, et al. (2017) Deep Sequencing Analysis of the Eha-Regulated Transcriptome of Edwardsiella tarda Following Acidification. Metabolomics (Los Angel) 7: 196. doi:10.4172/2153-0769.1000196

Page 10 of 10

27. Spaans SK, Weusthuis RA, van der Oost J, Kengen SW (2015) NADPHgenerating systems in bacteria and archaea. Front Microbiol 6: 742.

28. Srinivasa Rao PS, Lim TM, Leung KY (2003) Functional genomics approach to the identification of virulence genes involved in Edwardsiella tarda pathogenesis. Infect Immun 71: 1343-1351.

29. Stark RM, Suleiman MS, Hassan IJ, Greenman J, Millar MR (1997) Amino acid utilisation and deamination of glutamine and asparagine by Helicobacter pylori. J Med Microbiol 46: 793-800.

30. Hammond CE, Beeson C, Suarez G, Peek RM, Jr Backert S, et al. (2015) Helicobacter pylori virulence factors affecting gastric proton pump expression and acid secretion. Am J Physiol Gastrointest Liver Physiol 309: G193-G201.

31. Cooper CA, Mainprize IL, Nickerson NN (2015) Genetic, Biochemical, and Structural Analyses of Bacterial Surface Polysaccharides. Adv Exp Med Biol 883: 295-315

32. Locatelli FM, Goo KS, Ulanova D (2016) Effects of trace metal ions on secondary metabolism and the morphological development of Streptomycetes. Metallomics 8: 469-480.

33. Muramatsu MK, Brothwell JA, Stein BD, Putman TE, Rockey DD, et al. (2016) Beyond Tryptophan Synthase: Identification of Genes That Contribute to Chlamydia trachomatis Survival during Gamma Interferon-Induced Persistence and Reactivation. Infect Immun 84: 2791-2801.

34. Yan W, Wang H, Xu W, Wu K, Yao R, et al. (2012) SP0454, a putative threonine dehydratase, is required for pneumococcal virulence in mice. $\mathrm{J}$ Microbiol 50: 511-517.
35. Locher KP (2016) Mechanistic diversity in ATP-binding cassette (ABC) transporters. Nat Struct Mol Biol 23: 487-493.

36. Remy L, Carrière M, Derré-Bobillot A, Martini C, Sanguinetti M, et al. (2013) The Staphylococcus aureus Opp1 ABC transporter imports nickel and cobalt in zinc-depleted conditions and contributes to virulence. Mol Microbiol 8794: 730-743.

37. Furukawa Y, Inoue Y, Sakaguchi A, Mori Y, Fukumura T, et al. (2016) Structura stability of flagellin subunit affects the rate of flagellin export in the absence of Flis chaperone. Mol Microbiol 2102: 405-416.

38. Homma M, DeRosier DJ, Macnab RM (1990) Flagellar hook and hookassociated proteins of Salmonella typhimurium and their relationship to other axial components of the flagellum. J Mol Biol 13: 819-832.

39. Xu S, Peng Z, Cui B, Wang, T, Song Y, et al. (2014) FliS modulates FlgM activity by acting as a non-canonical chaperone to control late flagellar gene expression, motility and biofilm formation in Yersinia pseudotuberculosis. Environ Microbiol 16: 1090-1104.

40. Caselli A, Paoli P, Santi A, Mugnaioni C, Toti A, et al. (2016) Low molecular weight protein tyrosine phosphatase: Multifaceted functions of an evolutionarily conserved enzyme. Biochim Biophys Acta 1864: 1339-1355.

41. Mijakovic I, Grangeasse C, Turgay K (2016) Exploring the diversity of protein modifications: special bacterial phosphorylation systems. FEMS Microbiol Rev 40: 398-417. 